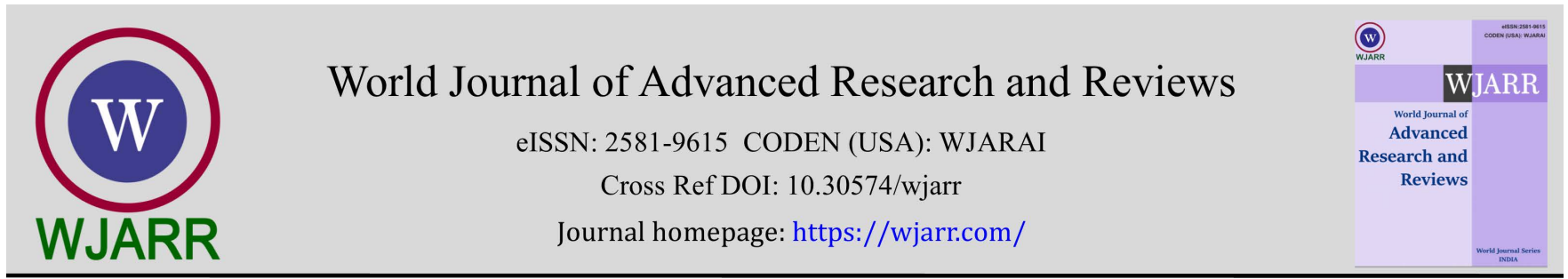

(RESEARCH ARTiCle)

Check for updates

\title{
Catalyzed-Mea conversion of Agro-biomass to paper-pulp: Influence of pulping additives and synergy effect on pulp screened yield
}

Henry Okwudili Chibudike 1, ${ }^{*}$, Nwaebuni Ebube Odega 2, Eunice Chinedum Chibudike ${ }^{3}$, Olubamike Adetutu Adeyoju ${ }^{4}$ and Nkemdilim Ifeanyi Obi ${ }^{5}$

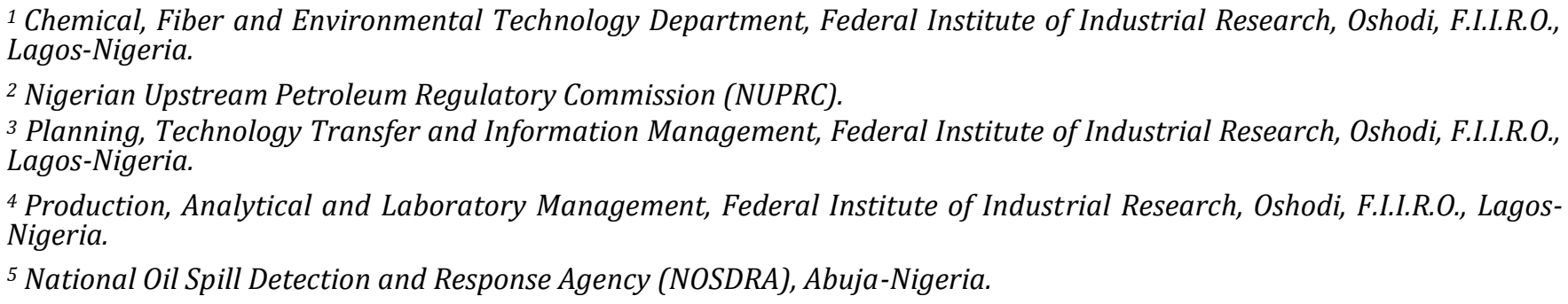

World Journal of Advanced Research and Reviews, 2021, 12(02), 392-400

Publication history: Received on 01 October 2021; revised on 09 November 2021; accepted on 11 November 2021

Article DOI: https://doi.org/10.30574/wjarr.2021.12.2.0594

\begin{abstract}
In this research work, the effect of three (3) pulping additives such as polysulfide, Anthraquinone and surfactant used in the monoethanolamine (MEA) pulping of agro-biomass, their possible interactions and synergy effect on pulp screened yield were investigated. The pulping conditions of the digester were adjusted so that the experimental design considered the following factors and levels: 75\% MEA charge, 150oC cooking temperature, 90minutes cooking time, 4 to 1 LiquorBiomass ratio. Factor 1: 0, 0.25 and 0.5\% Surfactant charge, Factor 2: 0, 2.0 and 4.0\% polysulfide charge, Factor 3: 0, 0.25 and $0.5 \%$ anthraquinone charge. The Agro-biomass was evaluated in terms of pulp screened yield. Heating time ranged from 5 to 45 minutes and maximum cooking time did not exceed 90minutes, liquor biomass ratio was 4 to 1 and Liquor charge was 75\% MEA. The yield for MEA with 4\% Polysulfide (PS) dosage without the inclusion of Surfactant and Anthraquinone was highest (59.08\%) in all the twenty seven (27) experimental runs, but furnished the highest reject $(12.26 \%)$ and an unimpressive screened yield of $46.82 \%$ standing amongst the least possible outcomes. The yield for MEA with $0.25 \%$ Anthraquinone (AQ) dosage without the inclusion of Surfactant and Polysulfide furnished a total yield of $50.32 \%$, pulp screened yield of $50.03 \%$ with a minimal reject of 0.29 showing to be more efficient than the use of polysulfide. Monoethanolamine (MEA) pulping with $0.5 \%$ surfactant (Surf.) dosage without the inclusion of other additives i.e. AQ and PS achieved 51.12\% total screened yield with a reject of only $0.33 \%$ furnishing the highest pulp screened yield (50.79\%) thereby showing more efficiency amongst the three (3) pulping additives investigated in this research study base on single use. However, the result obtained from the combination of the three (3) pulping additives furnished the highest screened yield (52.43) with $4.23 \%$ reject in scenario E, experiment No. 15, involving the combination of $0.25 \%$ surfactant, $0.25 \%$ anthraquinone and $4 \%$ polysulfide charge showing the best synergistic effect. Although the highest screened yield $(53.04 \%$ and the least reject $(0.13 \%)$ indicating the best possible outcome amongst the entire twenty seven (27) experimental runs came from the combination of $0.25 \%$ surfactant and $2 \%$ polysulfide charge. If we have to consider the use of surfactant and polysulfide alone, the best possible outcome came from the combination of $0.25 \%$ surfactant and $2 \%$ polysulfide charge in experiment 20 of scenario G. Analyses of the overall experimental results show that there is considerable advantage and a positive synergy effect in the use of additives in pulping operation.
\end{abstract}

\footnotetext{
${ }^{*}$ Corresponding author: Henry Okwudili Chibudike

Chemical, Fiber and Environmental Technology Department, Federal Institute of Industrial Research, Oshodi, F.I.I.R.O., LagosNigeria.
}

Copyright $(2021$ Author(s) retain the copyright of this article. This article is published under the terms of the Creative Commons Attribution Liscense 4.0. 
Keywords: MEA-Pulping; kraft; EFB of Oil Palm; Beating; Pulp Screen yield; Soda-Pulping; Paper-pulp

\section{Introduction}

Pulping is a process where the wood chips or other fibrous raw materials are ruptured mechanically, thermally, chemically or combinations of these treatments into a fibrous mass which known is as pulp. Chemical pulping is a process where the wood chips or fibrous raw materials are cooked in an aqueous solution at elevated temperatures and pressure with appropriate chemicals. Chemical pulping is chemically separating the fibrous fiber into pulps by degrading about $90 \%$ of the lignin from the materials and retaining most of the cellulose and hemicelluloses. The chemical pulping methods can be classified into two major principles namely; alkaline such as kraft process and soda process and acidic such as sulfite and bisulfite process. The kraft process is a modification of the soda process which utilizes sodium hydroxide $(\mathrm{NaOH})$ with the addition of sodium sulfate $\left(\mathrm{Na}_{2} \mathrm{SO}_{4}\right)$ into the cooking liquor system $[1,2]$. The Kraft pulping process is the most versatile and efficient method of pulp production and its versatility is anchored upon it ability to pulp almost any kind of wood successfully but it is always associated with severe environment pollution especially the air pollution. Prominent are the emission of fowl smelling and malodorous pollutants. The air pollution from the kraft pulping is a major concern with the emission of sulphur gases into the atmosphere with a rate of 0.3-3 kilograms per metric tonne (kg/t) of air-dried pulp (ADP) [3]. The four reduced sulphur gases are hydrogen sulfide, methyl mercaptan, dimethyl sulfide and dimethyl disulfide. The obnoxious odour of the gases even released from the advanced kraft mills. All the gases have extremely low odor thresholds, which indicated that long term exposure to these gases, the balance of ecosystem and even human health will be seriously interfered. In addition, strongly alkaline cooking liquors dissolve carbohydrates to a great extent with negative impact on pulp yield. Most annual plants have a high content of silica, which is dissolved to a high extent in the strongly alkaline cooking liquor and thus creates serious problems in the evaporators, the recovery boilers and in the causticizing plant $[4,5$ and 6$]$.

Nowadays ECF and TCF bleaching sequences are commercially available but its implementation requires significant changes at the pulping process in order to reduce the residual delignification levels and also increase the pulping yield. The need to increase the delignification efficiency of the pulping process lead to the concept of the modified pulping process.

\section{Experimental}

\subsection{Materials}

EFB of Oil Palm was collected from a palm plantation at Okiti Pupa in Ekiti State, Nigeria. The raw material (EFB) was shredded and dried to about $85 \%$ dryness in an acclimated room $\left(23.0 \pm 1.0^{\circ} \mathrm{C}\right.$ and $50.0 \pm 2.0 \%$ moisture $)$ and stored in polyethylene bags for further use.

\subsection{Methods}

After a thorough cleaning process, $2 \mathrm{~kg}$ of air-dry sample (EFB) was loaded into a $15 \mathrm{~L}$ capacity batch reactor (digester) with eight (8) liters of 75\% Monoethanolamine at liquor-sample ratio of 1:4. The pulping condition employed in this research study was based on results from previous pulping experiments which centered on the use of the following optimum cooking conditions: $75 \%$ Monoethanolamine liquor charge, $150 \mathrm{oC}$ maximum cooking temperature, and 90minutes maximum cooking time. The experimental design employed in this research study involves cooking operations catalyzed by the addition of surfactant, anthraquinone and polysulfide in respective ratios of Factor 1: 0 , 0.25 and $0.5 \%$ Surfactant charge, Factor 2: $0,2.0$ and 4.0\% polysulfide charge, and Factor 3: $0,0.25$ and $0.5 \%$ anthraquinone charge. The experimental design had 27 treatments $(3 \times 3 \times 3)$ and 2 replicates. In each cooking operation, the lid of the digester was firmly bolted to prevent leakage, the digester was switched on and the time of rise of temperature and pressure was noted at intervals of five (5) minutes. The content of the digester was stirred while in operation by rotating the vessel via a motor connected through a rotary axle to a control unit, including measurement and control instruments of pressure and temperature, to facilitate attainment of the working temperature $\left(5^{\circ} \mathrm{C} / \mathrm{min}\right)$. The digester mounted in the Pulp and Paper Research Laboratory of the Federal Institute of Industrial Research, Oshodi, (F.I.I.R.O.), Lagos-Nigeria is furnished with an outer electrical heating jacket. The pulping temperatures gradually rose to a maximum temperature of $150 \mathrm{oC}$ for periods of 59 minutes and remain steady for a period of 31 minutes in each cooking operation. The digester was switched off after maximum cooking periods of 90 minutes from start of operation and allowed to cool below $60 \mathrm{oC}$ before the content were blown down. The resultant pulp was subjected to thorough washing with plenty of water. When it was observed that subsequent washing resulted in no further change in color, the pulp was transferred into the valley beater for processing into a more refined pulp. 
Table 1 Experimental pulping conditions

\begin{tabular}{|l|c|}
\hline Parameters & Cooking Condition \\
\hline MEA Charge (\%) & 75 \\
\hline Surfactant charge (\% on O.D. sample) & $0,0.25,0.5$ \\
\hline Anthraquinone charge (\% on O.D. sample) & $0,0.25,0.5$ \\
\hline Polysulfide charge (\% on O.D. sample) & $0,2.0,4.0$ \\
\hline Maximum Temp. $\left({ }^{\circ} \mathrm{C}\right)$ & 150 \\
\hline Heating Time (minutes) & 59 \\
\hline Maximum Cooking Time (minutes) & 90 \\
\hline Wood/Liquor ratio & $4 / 1$ \\
\hline
\end{tabular}

\section{Results and discussion}

Considering the experimental design, the results were statistically analysed in order to detect the effect of the additives over the main pulping process variables. All analytical tests were carried out in duplicate. Statistical analysis was performed using the Design Expert software. Data were analysed by the analysis of variance (ANOVA), and p- value lower than 0.05 was considered significant in surface response analysis.

Table 2 Experimental Pulping Conditions and Results

\begin{tabular}{|c|c|c|c|c|c|c|c|}
\hline $\begin{array}{l}\text { Pulping } \\
\text { Scenarios/ } \\
\text { Batches }\end{array}$ & $\begin{array}{l}\text { Experiment } \\
\text { No. }\end{array}$ & $\begin{array}{l}\text { Surf. (\%) base on } \\
\text { oven dried }\end{array}$ & $\begin{array}{c}\text { AQ (\%) base } \\
\text { on } \\
\text { oven dried }\end{array}$ & $\begin{array}{c}\text { PS (\%) } \\
\text { base } \\
\text { on oven } \\
\text { dried }\end{array}$ & $\begin{array}{l}\text { Total } \\
\text { Yield } \\
(\%)\end{array}$ & $\begin{array}{c}\text { Screened } \\
\text { Yield } \\
(\%)\end{array}$ & $\begin{array}{c}\text { Reject } \\
\text { (\%) }\end{array}$ \\
\hline \multirow[t]{3}{*}{ A } & 1 & 0 & 0 & 0 & 49.32 & 49.07 & 0.25 \\
\hline & 2 & 0 & 0 & 2 & 54.27 & 48.39 & 5.88 \\
\hline & 3 & 0 & 0 & 4 & 59.08 & 46.82 & 12.26 \\
\hline \multirow[t]{3}{*}{ B } & 4 & 0 & 0.25 & 0 & 50.32 & 50.03 & 0.29 \\
\hline & 5 & 0 & 0.25 & 2 & 52.11 & 50.65 & 1.46 \\
\hline & 6 & 0 & 0.25 & 4 & 57.77 & 47.79 & 9.98 \\
\hline \multirow[t]{3}{*}{$\mathrm{C}$} & 7 & 0 & 0.5 & 0 & 49.87 & 49.36 & 0.51 \\
\hline & 8 & 0 & 0.5 & 2 & 52.10 & 50.89 & 1.21 \\
\hline & 9 & 0 & 0.5 & 4 & 57.00 & 48.46 & 8.54 \\
\hline \multirow[t]{3}{*}{ D } & 10 & 0.25 & 0 & 0 & 49.98 & 49.79 & 0.19 \\
\hline & 11 & 0.25 & 0 & 2 & 52.66 & 50.57 & 2.09 \\
\hline & 12 & 0.25 & 0 & 4 & 58.12 & 49.00 & 9.12 \\
\hline \multirow[t]{3}{*}{$\mathrm{E}$} & 13 & 0.25 & 0.25 & 0 & 53.17 & 53.04 & 0.13 \\
\hline & 14 & 0.25 & 0.25 & 2 & 51.22 & 50.10 & 1.12 \\
\hline & 15 & 0.25 & 0.25 & 4 & 56.66 & 52.43 & 4.23 \\
\hline \multirow[t]{2}{*}{$\mathrm{F}$} & 16 & 0.25 & 0.5 & 0 & 49.99 & 49.69 & 0.21 \\
\hline & 17 & 0.25 & 0.5 & 2 & 52.22 & 50.70 & 1.52 \\
\hline
\end{tabular}




\begin{tabular}{|c|c|c|c|c|c|c|c|}
\cline { 2 - 8 } & 18 & 0.25 & 0.5 & 4 & 57.01 & 49.87 & 7.14 \\
\hline \multirow{3}{*}{$\mathrm{G}$} & 19 & 0.5 & 0 & 0 & 51.12 & 50.79 & 0.33 \\
\cline { 2 - 8 } & 20 & 0.5 & 0 & 2 & 53.33 & 51.76 & 1.57 \\
\cline { 2 - 8 } & 21 & 0.5 & 0 & 4 & 56.56 & 51.01 & 5.55 \\
\hline \multirow{3}{*}{$\mathrm{H}$} & 22 & 0.5 & 0.25 & 0 & 50.19 & 49.77 & 0.42 \\
\cline { 2 - 8 } & 23 & 0.5 & 0.25 & 2 & 52.22 & 50.83 & 1.39 \\
\cline { 2 - 8 } & 24 & 0.5 & 0.25 & 4 & 58.14 & 48.15 & 9.99 \\
\hline \multirow{3}{*}{$\mathrm{I}$} & 25 & 0.5 & 0.5 & 0 & 50.75 & 50.46 & 0.29 \\
\cline { 2 - 8 } & 26 & 0.5 & 0.5 & 2 & 53.00 & 51.78 & 1.22 \\
\cline { 2 - 8 } & 27 & 0.5 & 0.5 & 4 & 57.47 & 51.80 & 5.67 \\
\hline
\end{tabular}

Surf--Surfactant; $\mathrm{AQ}=$ Anthraquinone; $\mathrm{PS}=$ Polysulfide

Table 3 ANOVA for Response Surface Quadratic Model [Partial sum of squares]

\begin{tabular}{|c|c|c|c|c|c|c|}
\hline Source & Sum of Squares & DF & Mean Square & F Value & Prob $>$ F & \\
\hline Model & 4.83 & 9 & 0.54 & 0.40 & 0.9063 & not significant \\
\hline A & 0.83 & 1 & 0.83 & 0.62 & 0.4478 & \\
\hline B & $5.064 \mathrm{E}-003$ & 1 & $5.064 \mathrm{E}-003$ & $3.809 \mathrm{E}-003$ & 0.9520 & \\
\hline C & 0.69 & 1 & 0.69 & 0.52 & 0.4884 & \\
\hline A2 & 0.030 & 1 & 0.030 & 0.023 & 0.8836 & \\
\hline B2 & 0.85 & 1 & 0.85 & 0.64 & 0.4433 & \\
\hline C2 & 0.13 & 1 & 0.13 & 0.097 & 0.7614 & \\
\hline AB & $7.673 \mathrm{E}-003$ & 1 & $7.673 \mathrm{E}-003$ & $5.770 \mathrm{E}-003$ & 0.9409 & \\
\hline AC & 0.100 & 1 & 0.100 & 0.075 & 0.7899 & \\
\hline BC & 0.036 & 1 & 0.036 & 0.027 & 0.8730 & \\
\hline Residual & 13.30 & 10 & 1.33 & - & - & \\
\hline Cor Total & 18.12 & 19 & - & - & - & \\
\hline
\end{tabular}

The "Model F-value" of 0.40 implies the model is not significant. A total of 20 experiments were found to be sufficient to calculate the coefficients of the second-order polynomial regression model for three variables. The process order here is to develop a quadratic term of a polynomial model, so we consider equation 1 and 2:

The behavior of the cooking process is explained by the empirical second order polynomial model. Here $Y$ is the Pulp Screened Yield in \%, where A $=\%$ Weight of Biomass (before pulping), B= \%Weight of Biomass (after pulping) and $\mathrm{R}=\%$ Weight of Reject.

$\mathrm{Y} \%=\mathrm{Ao}+\mathrm{A} 1 \mathrm{X} 1+\mathrm{A} 2 \mathrm{X} 2+\mathrm{A} 3 \mathrm{X} 3+\mathrm{A} 12 \mathrm{X} 1 \mathrm{X} 2+\mathrm{A} 13 \mathrm{X} 1 \mathrm{X} 3+\mathrm{A} 23 \mathrm{X} 2 \mathrm{X} 3+\mathrm{A} 11 \mathrm{X} 12+\mathrm{A} 22 \mathrm{X} 22+\mathrm{A} 33 \mathrm{X} 32$ . .1

$\mathrm{Y} \%=\mathrm{A}-\mathrm{B}-\mathrm{R}$

A

Final Equation in Terms of Coded Factors (Equation 3): Pulp Screened yield $=+51.23$

$+0.43 * \mathrm{~A}-0.029 * \mathrm{~B}+0.33^{*} \mathrm{C}-0.091 * \mathrm{~A} 2-0.49 * \mathrm{~B} 2-0.18^{*} \mathrm{C} 2+0.044^{*} \mathrm{~A} * \mathrm{~B}+0.16^{*} \mathrm{~A} * \mathrm{C}+0.076^{*} \mathrm{~B} * \mathrm{C}$ . .3 
The equation in terms of actual factors can be used to make predictions about the response for given levels of each factor. However, to evaluate this quadratic model, we regress predicted vs. actual (observed) values or vice versa and compare slope and intercept parameters against the 1:1 line.

The residuals are represented graphically by means of a residual plot as shown in figure 1 and 2 . This normal probability plot indicates whether the residuals follow a normal distribution, thus follow the straight line. Here, the scatter had a definite pattern along the straight line which indicates that a transformation of the response may provide a better analysis.

Final Equation in Terms of Actual Factors (Equation 4): Pulp Screened yield $=+50.01638$

$+1.61395 *$ Surfactant+3.33136*Anthraquinone+0.22694*Polysulfide-1.45719*Surfactant2-7.85051*Anthraquinone2

0.045088*Polysulfide2+0.70752*Surfactant*Anthraquinone+0.32910*Surfactant*Polysulfide+0.15130*Anthraquinon e * Polysulfide.

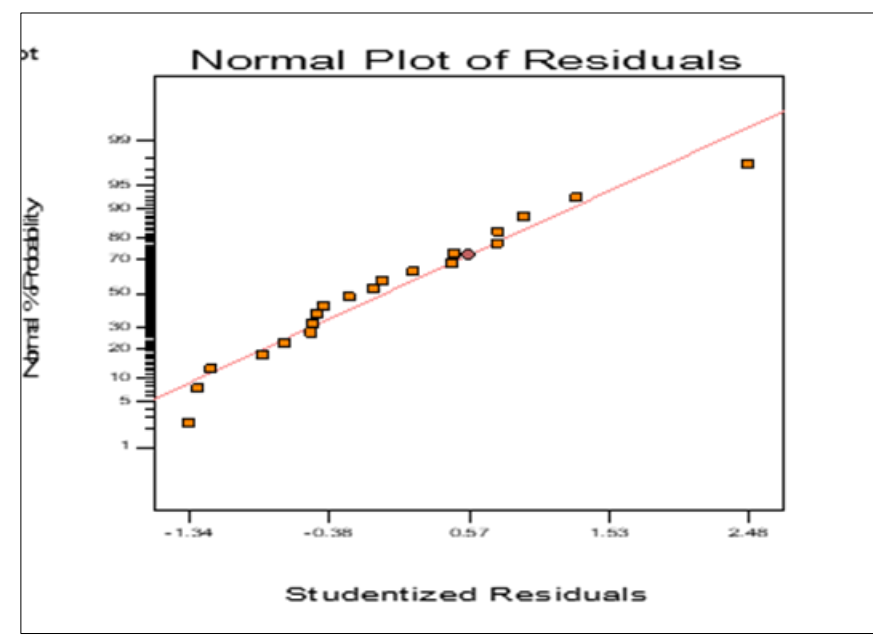

Figure 1 Normal probability plot of studentized residuals

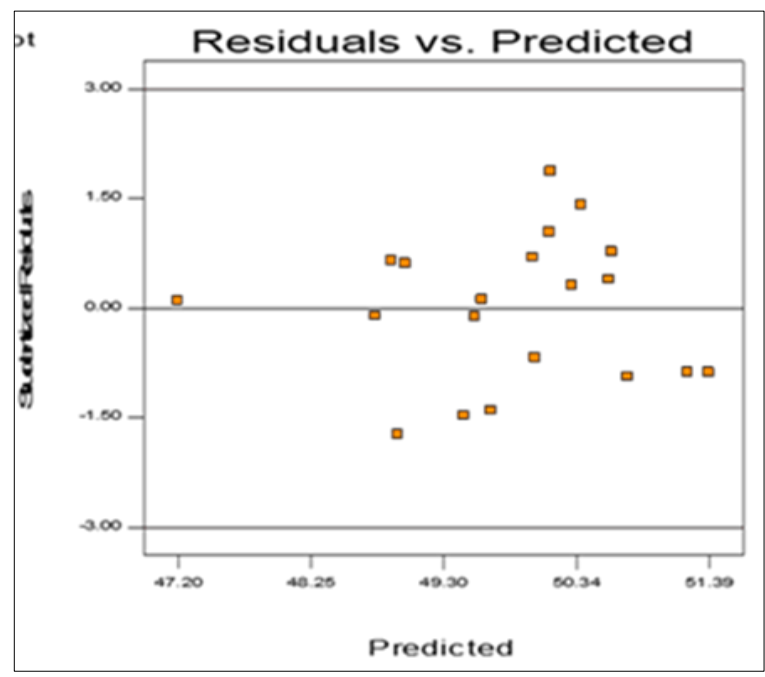

Figure 3 Studentized residuals versus predicted values

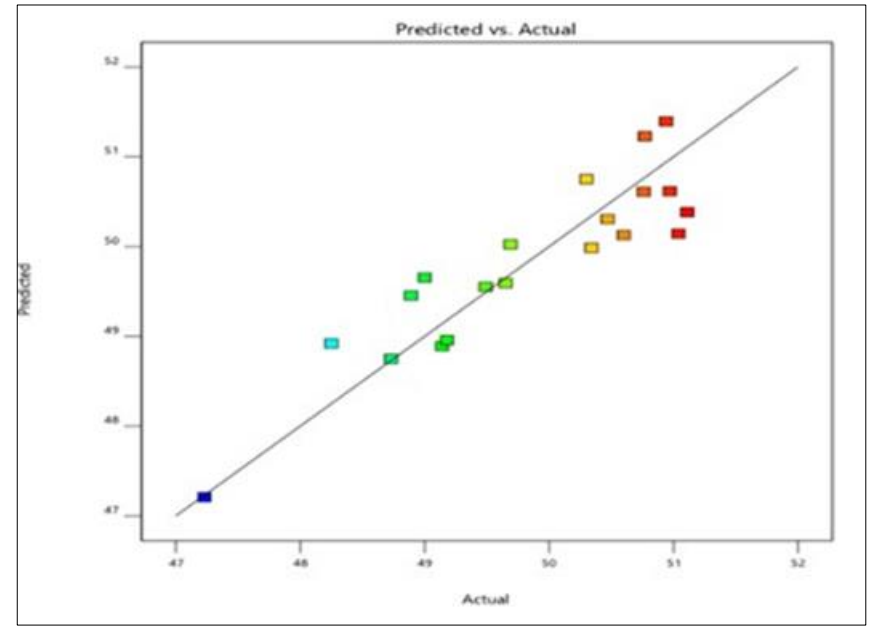

Figure 2 Plot of Predicted vs Actual Values

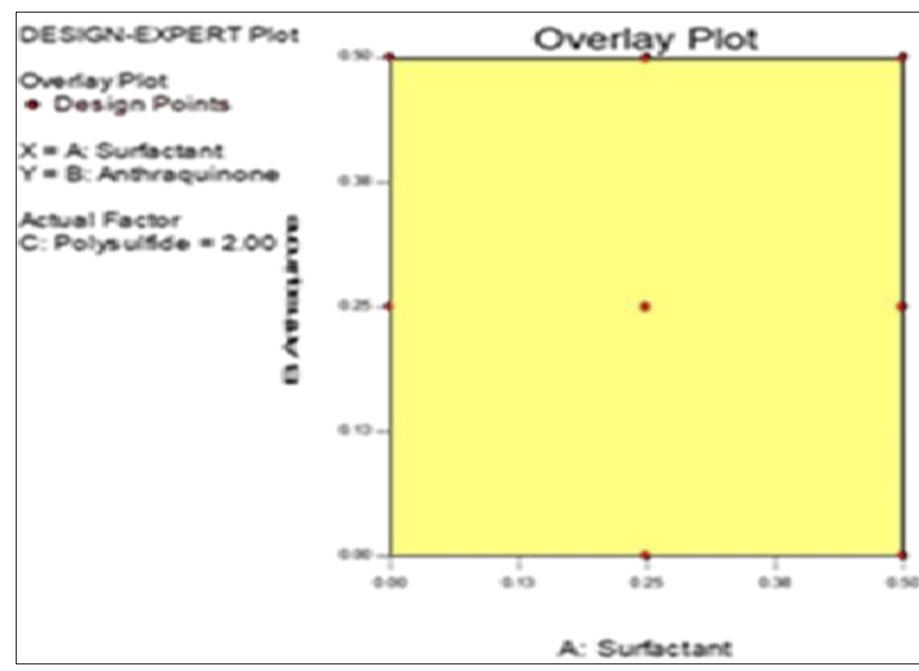

Figure 4 Overlay Contour of Graphical Optimization solution for the AQ and Surf interaction

Here in figure 3, the residual plots are spread around the horizontal axis, indicating the appropriateness of the linear regression (quadratic) model. 


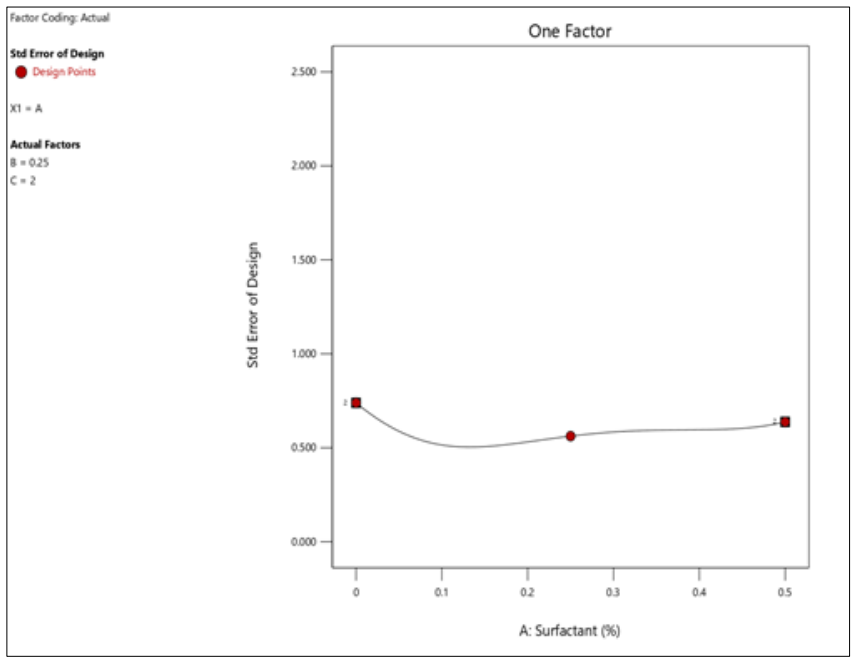

Figure 5 Response Surface Plot showing how the response changes as each factor moves

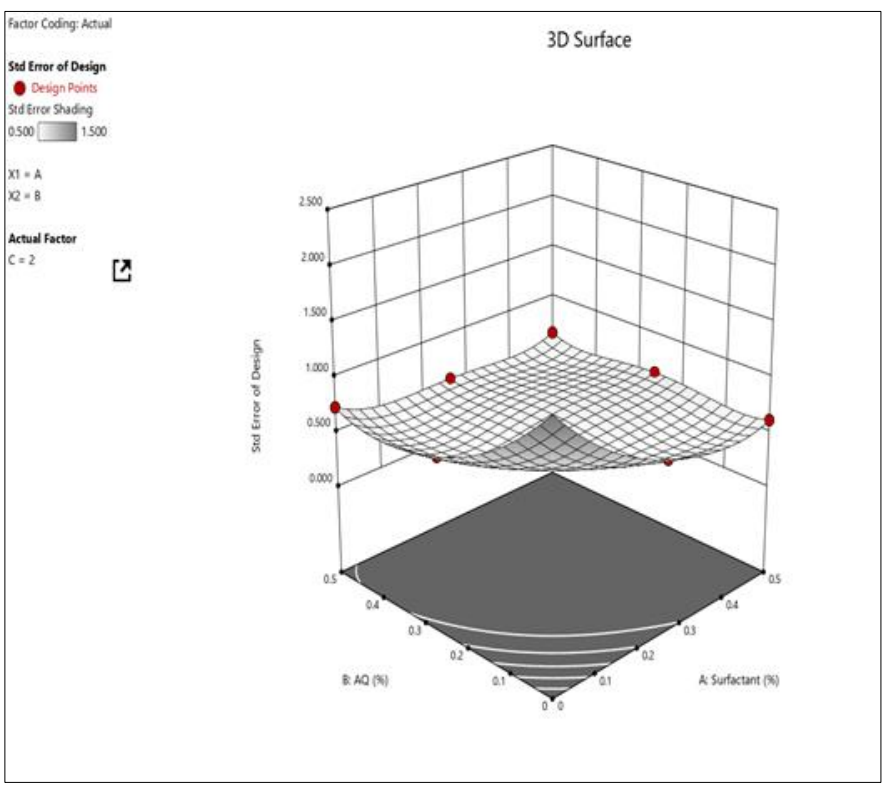

Figure 7 3D Surface Model Graph Showing Multiple Interactions

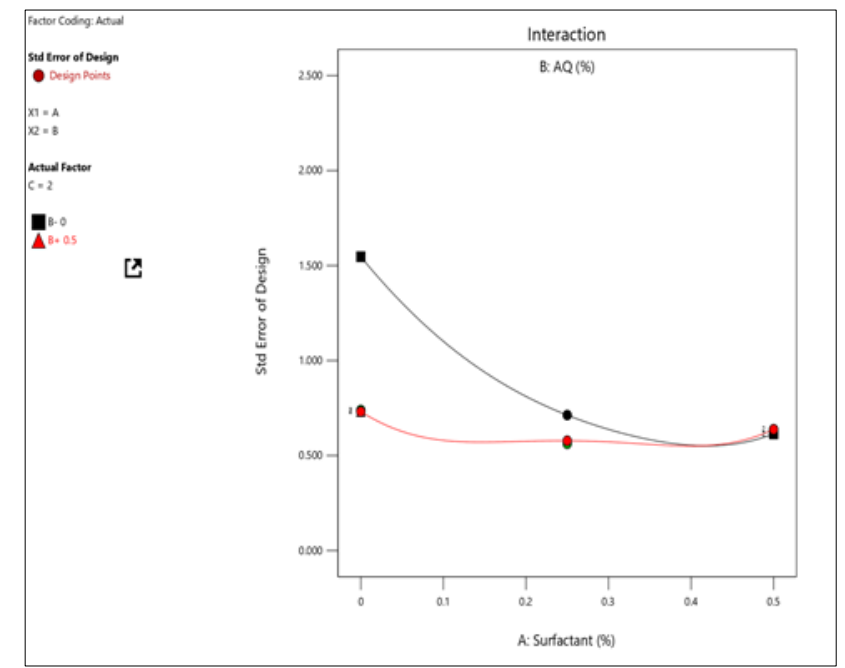

Figure 6 Response Surface Multiple Interaction Plot

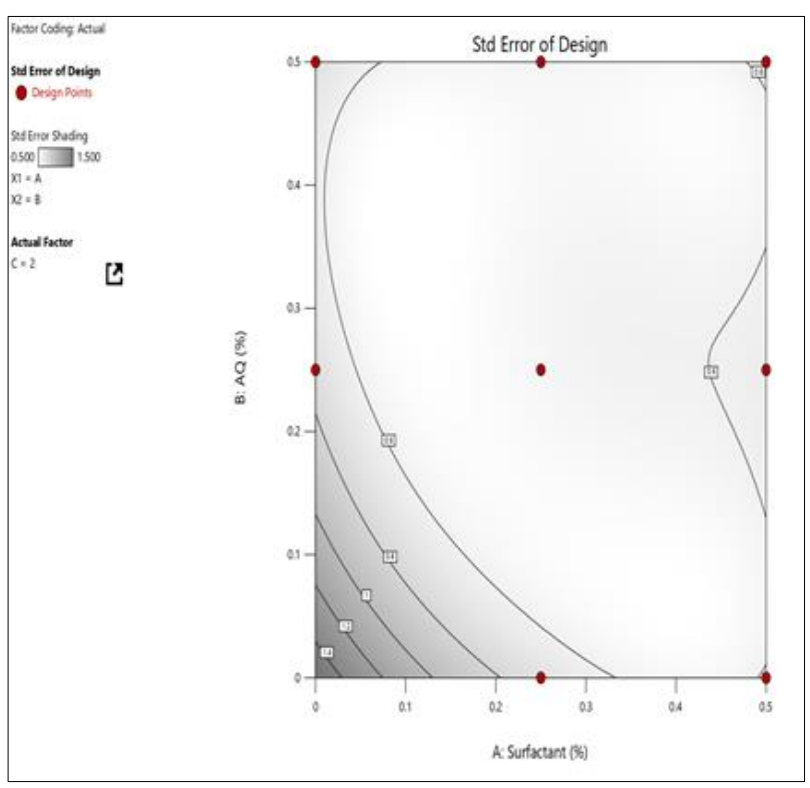

Figure 8 Response Surface Contour Plot showing various Design Points

\subsection{Effect of Pulping Additives on Pulp Yield}

The pulping conditions and results are given in Table 2. Anthaquinone, Surfactant and Polysulfide were tested up to the limit of the yield growing. Monoethanolamine pulping without any of the three (3) additives furnished $49.07 \%$ pulp screen yield, a value unexpectedly higher than values obtained with monoethanolamine pulping involving only polysulfide either with $2 \%$ or $4 \%$ dosage. In these pulping scenarios (A), the higher the dosage of polysulfide, the lower the pulp yield and the greater the value of reject which consequently resulted in a low value of screened yield. Monoethanolamine pulping with surfactant alone furnished better result with either dosage, i.e. $0.25 \%$ surfactant charge furnishing $49.79 \%$ pulp screen yield with only $0.19 \%$ reject, and $0.50 \%$ surfactant charge furnishing $50.79 \%$ pulp screened yield with only $0.33 \%$ reject, a value expectedly higher than values obtained when pulping with monoethanolamine alone. MEA-pulping with anthraquinone alone furnished better result with either dosage, i.e. $0.25 \%$ AQ charge furnishing $50.03 \%$ pulp screen yield with only $0.29 \%$ reject, and $0.50 \%$ AQ charge furnishing $49.36 \%$ pulp screened yield with only $0.51 \%$ reject, a value expectedly higher than values obtained when pulping with monoethanolamine alone. 


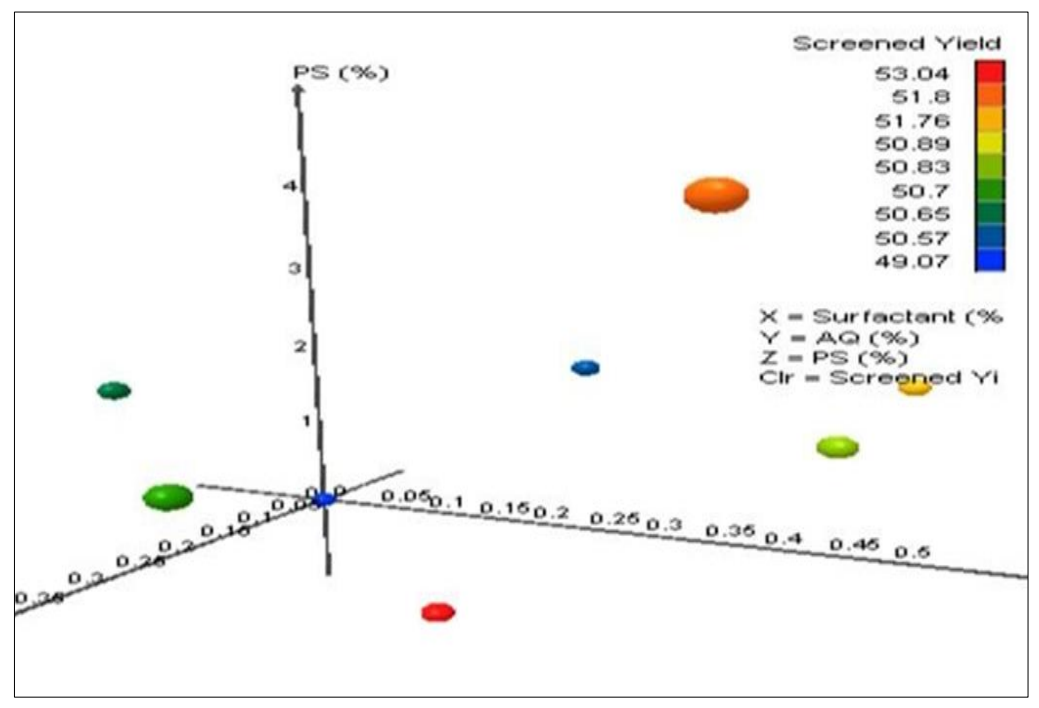

Figure 9 Model Graph Showing the Effect of Additives on Pulp Screened Yield

\subsection{Synergy Effect of Pulping Additives on Screen Yield and Reject in the Best Possible Scenarios}

Scenario A, experiment 1 though furnished the highest screened yield without additives, 49.07 is taken as control or reference point. The synergy effect of $0.25 \%$ anthraquinone charge and $2 \%$ polysulfide charge furnished the highest pulp screen yield, $50.65 \%$ in experiment 5 of scenario B. In experiment 8 of scenario C, the synergy effect $0.5 \%$ anthraquinone charge and $2 \%$ polysulfide charge furnished the highest pulp screened yield, $50.89 \%$ which gave a better result than that obtained in experiment 5 of Scenario B. The combination of $0.25 \%$ surfactant charge and $2 \%$ polysulfide charge in experiment 11 of scenario D furnished a higher screened yield, $50.57 \%$, compared to that obtained in scenarios $A$ and $B$, but only second to the value obtained in scenario $C$.

Experiment 13 of scenario E furnished the best result among all the entire twenty seven (27) experimental runs conducted, involving equal charge of surfactant $(0.25 \%)$ and anthraquinone $(0.25 \%)$ alone furnishing the highest screened yield value of $53.04 \%$ and the least reject value of $0.13 \%$ with Intrinsic viscosity of $1233 \mathrm{~cm}^{3} / \mathrm{g}$.

Table 4 Pulping Conditions and Results of Best Possible Scenarios/Outcome

\begin{tabular}{|c|c|c|c|c|c|c|c|}
\hline $\begin{array}{l}\text { Best } \\
\text { Possible } \\
\text { Scenarios }\end{array}$ & $\begin{array}{l}\text { Experiment } \\
\text { No. }\end{array}$ & $\begin{array}{ll}\begin{array}{l}\text { Surf. } \\
\text { base }\end{array} & (\%) \\
\text { on } & \text { oven } \\
\text { dried } & \\
\end{array}$ & $\begin{array}{ll}\text { AQ (\%) base } \\
\text { on } \\
\text { dried }\end{array}$ & $\begin{array}{l}\text { PS (\%) base } \\
\text { on oven } \\
\text { dried }\end{array}$ & $\begin{array}{l}\text { Total } \\
\text { Yield } \\
(\%)\end{array}$ & $\begin{array}{l}\text { Screened } \\
\text { Yield (\%) }\end{array}$ & $\begin{array}{l}\text { Reject } \\
(\%)\end{array}$ \\
\hline \multirow[t]{2}{*}{$\mathrm{E}$} & 13 & 0.25 & 0.25 & 0 & 53.17 & 53.04 & 0.13 \\
\hline & 15 & 0.25 & 0.25 & 4 & 56.66 & 52.43 & 4.23 \\
\hline$G$ & 20 & 0.5 & 0 & 2 & 53.33 & 51.76 & 1.57 \\
\hline \multirow[t]{2}{*}{ I } & 26 & 0.5 & 0.5 & 2 & 53.00 & 51.78 & 1.22 \\
\hline & 27 & 0.5 & 0.5 & 4 & 57.47 & 51.80 & 5.67 \\
\hline
\end{tabular}

Scenario $\mathrm{F}$ involved the combination of the entire three (3) pulping additives, with experiment 17 conducting0.25\% surfactant charge, $0.5 \%$ anthraquinone charge and $2 \%$ polysulfide charge. This scenario furnished pulp screened yield value of $50.70 \%$ lower than those obtained in scenario C, E, G, H and I. Observing the experimental outcome of scenarios $\mathrm{H}$ and I involving the combination of the three pulping additives employed in this research study, it is hence ascertained that the synergy effect of the three pulping additives has no positive correlation with increase in pulp screened yield i.e. the highest charge of $0.5 \%$ surfactant, $0.5 \%$ anthraquinone and $4.0 \%$ polysulfide did not significantly influence the increase in pulp screened yield (51.80\%). The reject content decreased with the exclusion of Polysulfide additive in the pulping operation. It was further observed that increase in the dosage of the three (3) additives (Surfactant, 0.5, Anthraquinone, 0.5 and Polysulfide, 4) brought about increase in reject. It is suspected that this outcome could come 
about due to increase in the rate of delignification, solubilization and consequent degradation of cellulosic biomass. The highest yield was obtained with the $0.25 \%$ AQ and $0.25 \%$ Surfactant dosage alone.

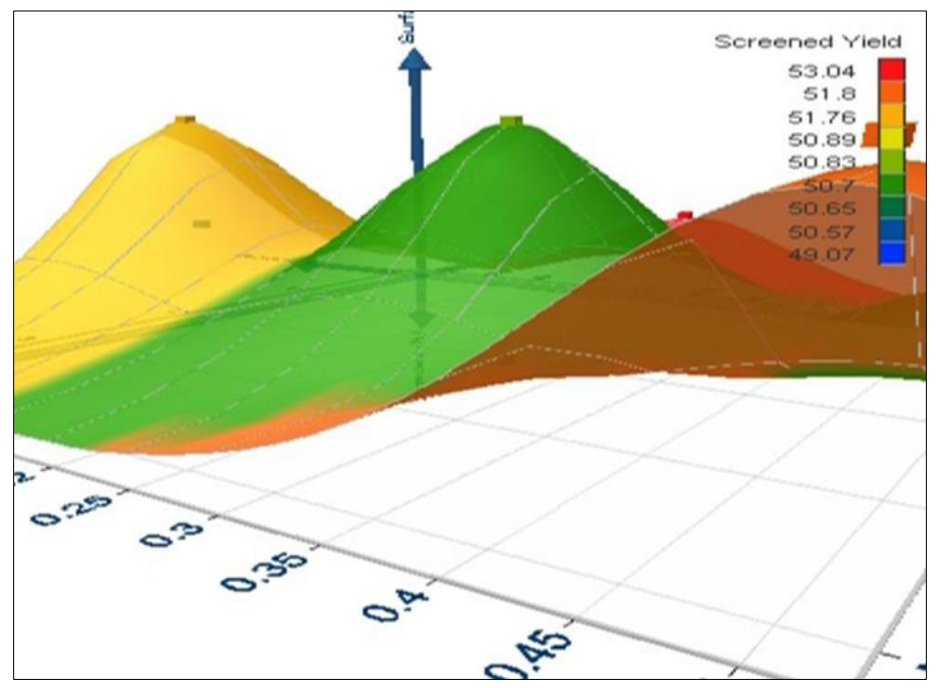

Figure 10 Model Graph Showing the Effect of Interaction and Synergy on Pulping Additives

The synergy effect of the surfactant and anthraquinone content was not enough to avoid rejects. As shown in Table 3 and 4 , the highest dosage of the admixture of the three additives, did not yield the best screened yield. As a matter of fact, the higher the dosage the more the reject contents and this negative effect is exceptionally more pronounced with Polysulfide which produced the highest reject content in virtually all its combinations.

The anthraquinone addition increased the MEA pulping screened yield level and, for some dosages, this yield turns out higher than that of the MEA-surfactant yield with polysulfide addition recording the least screened yield. However for surfactant treatments, reject content increased for same kappa number. The same came about with the anthraquinone treatment. Surfactant addition alone did not show excellent results for screened yield, but kept a low reject content. The surfactant and anthraquinone equivalent dosage for the MEA-pulping operation can be increased if aimed at converting rejects in screened yield.

In this research study, it is suspected that surfactant promotes a dispersant action and also increases cellulosic biomass impregnation, thereby complementing the anthraquinone chemistry action in protecting carbohydrates and in lignin solubilization.

\section{Conclusions}

An interesting example of exploitation of natural resources is the Nigerian Oil Palm EFBs (empty fruit bunches). The fact that palm trees are chiefly grown in the southern part of Nigeria and EFB which is the by-product of palm oil extraction process is produced in abundance as waste materials puts it in a position of advantage over some other raw material sources for paper production.

In a world where virgin pulp sources are scarce, and environmental concerns require reduction in cutting down green forest, EFB of Oil Palm could become a good source of fiber alternative to wood. To discourage deforestation, and reduce the amount of wastes that are sent to landfill, attention should be directed towards the use of EFB fibre as

an alternative source of raw material in the Pulp and Paper Industry. If usefully utilized, these EFBs which constitute environmental nuisance and nightmare in communities where palm oil is largely processed would be of good economic benefit to the economy of Nigerian and other tropical regions of the world where Oil Palms are grown. Pulping is a chemical-technological process for the production of cellulose fibers from woods and other plant materials. The search for local long fiber pulp material which can be easily propagated remains one of the most important key desirderatum for the eventual resuscitation of the present mom bund paper industries of Nigeria. One important way of stemming the tide of imports is to find a good substitute to fine pulp for the use of the Nigeria paper companies when they eventually start producing. Besides being an innovation and new entry into the pulp map, the EFB fiber can become the best gift of FIIRO into the future pulp market of the tropical world. 
Considering the experimental design, results were analyzed in order to determine the effect of the additives and their associated synergy over the main monoethanolamine pulping process optimum condition. The pulp yield is one of the pulping process parameters of great importance due to its economic advantage but based on the overall result of the experimental investigation conducted, the combination of use of the three pulping additives is only recommended in the same pulping operation as presented in table 3. The addition of small amounts of anthraquinone presented some advantages which include; Increase in delignification rate of EFB, stabilization of carbohydrates content of EFB, Promotes good chemical and physical characteristics in pulps and paper sheets. Sutfactants, anthraquinone and polysulfide have proofed to be effective additives for monoethanolamine pulping. Higher yields and faster pulping rates were obtained through their use with agro-biomass both individually and in their combination. The mechanism, although not yet understood, probably involves a catalytic redox cycle. Oxidation of carbohydrate end-groups is almost certainly part of the cycle. Reduction of one or more functional groups in lignin or lignin-derived intermediates may well complete the cycle. However, some oxidation of lignin may also occur. With the use of pulping additives like anthraquinone, surfactants, polysulfide and their conjunct use to enhance efficient delignification, MEA- pulping of EFB require less chemical consumption with higher pulp yield than the soda process without environmental damage due to lack of sulphur emissions. Also, it is considered to be suitable for small scale mills.

\section{Compliance with ethical standards}

\section{Acknowledgments}

The Federal Institute of Industrial Research, Oshodi, (FIIRO), Nigeria, provided Research Support and funding for this project and also for participation in scientific conferences. I use this opportunity to appreciate the staff and student on industrial training at the pulp and paper research laboratory of the Federal Institute of Industrial Research Oshodi, Lagos, who participated in sample preparation for chemical analyses. I also wish to express my heartfelt gratitude to the staff of Planning, Technology Transfer and Information Management F.I.I.R.O for providing support during the statistical analysis of experimental results and also staff of National Oil Spill Detection and Response Agency (NOSDRA) for providing valuable advice on prevention of environmental pollution, enhancing sustainable development. A deep gratitude goes to staff of Nigerian Upstream Petroleum Regulatory Commission for giving me the much needed inspiration for isolation, purification and use of lignin (incrusting material/wastes) from the pulp production process as an alternative fuel for aircraft.

\section{Disclosure of conflict of interest}

There is no conflict of interest amongst the co-authors of this manuscript.

\section{References}

[1] Biermann JC. Handbook of Pulping and Paper making. 2nd Edition, Academic Press, California, USA. Casey J.P., (2000) Pulp and Paper, Chemistry and Technology, Interscience Publishers, Inc., New York. 1996; 389 - $399: 415$.

[2] Casey JP. Pulp and Paper, Chemistry and Technology, Interscience Publishers, Inc., New York. 2000; 389 - 399: 415.

[3] Chibudike HO. Catalytic Enhancement of Monoethanolamine Pulping Process, PhD Thesis, International University, Bamenda (IUB), Cameroon. 2019; 72-92.

[4] Grace, T. M., Malcolm, E. W., and Kocurek, M. J. (eds.). 1989. Pulp and Paper Manufacture, Vol. 5. Alkaline Pulping. Joint Textbook Committee of the Paper Industry, Atlanta. 637 pp.

[5] Heimburger, S. A., Blevins, D. S., Bostwick, J. H., and Donnini, G. P. 1988a. Kraft mill bleach plant effluents: recent developments aimed at decreasing their environmental impact, part 1. Tappi Journal 71 (10): 51-60.

[6] Sjöström E. Wood Chemistry: Fundamentals and Applications Gulf Professional Publishing, - Nature - 2nd Ed. 1993; 293.

[7] Smook GA. Handbook for pulp and paper technologists, 2nd ed.,p. 210. Vancouver, Canada, Angus Wilde Publications. 1992.

[8] Smook GA, Kocurek MJ. Joint Textbook Committee of the Paper Industry, Technical Association of the Pulp and Paper Industry", Canadian Pulp and Paper Association. 1992.

[9] World Bank. The World Bank annual report 1998 (English). Washington DC; World Bank. 1998. 